\title{
PENGEMBANGAN MODEL PEMBELAJARAN SHOOTING DALAM PERMAINAN BOLA BASKET
}

\author{
Indrayogi ${ }^{1}$ dan Bhakti Muda Heryanto ${ }^{2}$ \\ Universitas Majalengka, Indonesia \\ indrayogi13@gmail.com
}

\begin{abstract}
ABSTRAK. Penelitian ini bertujuan menghasilkan model pembelajaran shooting dalam permainan bola basket untuk meningkatkan kemampuan teknik dasar shooting dalam permainan bola basket melalui studi pengembangan model. Metode penelitian ini adalah penelitian yang mengacu pada model pengembangan dari Borg dan Gall yang telah divariasi, yaitu (1) melakukan penelitian model awal, (2) pembuatan produk baru yang berupa model pembelajaran shooting bola basket, (3) Validasi Ahli Pembelajaran dan Ahli Praktisi Basket, (4) melakukan uji coba skala kecil 16 siswa, (5) revisi produk oleh ahli pembelajaran dan ahli praktisi basket, (6) melakukan uji coba skala besar 31 siswa, (7) revisi produk berdasarkan kegiatan uji coba kelompok besar. Hasil akhir produk pengembangan dari hasil revisi produk akhir yaitu model pembelajaran shooting bola basket. Teknik analisis data yang digunakan adalah deskriptif persentase dan teknik analisis kualitatif. Dari data yang ada maka dapat disimpulkan bahwa pengembangan model pembelajaran shooting bola basket dapat digunakan dalam proses pembelajaran.
\end{abstract}

Kata Kunci: pengembangan model; pembelajaran shooting; permainan bola basket

\section{Pendahuluan}

Bola basket merupakan olahraga yang terus berkembang setiap waktu seiring perkembangan teknologi pada saat ini. Semakin ke depan peraturan bola basket juga mengalami perubahanperubahan yang semakin kompleks. Perkembangan ilmu teknologi dan komunikasi yang semakin pesat dalam bidang pendidikan menjadi penting terutama dalam bidang kepelatihan khususnya bola basket. Salah satu cara penggunaan berbagai macam media dalam pembelajaran sesuai dengan tujuan materi dan karakteristik atlet itu sendiri.

Menurut Kosasih dalam Hasan, (2016), Permainan bola basket dibagi menjadi empat quarter, setiap quarter berdurasi sepuluh menit. Dengan demikian dapat dibayangkan bagaimana para pemain berusaha untuk mencetak 2 point sebanyak-banyaknya dan pemain yang mempertahankan keranjang atau ringnya agar tidak kemasukan bola. Tembakan atau shooting adalah usaha memasukkan bola ke keranjang. Menurut Ahmadi (2007) tembakan atau shooting merupakan usaha memasukkan bola ke keranjang.

Sedangkan menurut Kosasih dalam Ahmad, (2016), Shooting adalah skill dasar bolabasket yang paling dikenal dan di gemari setiap pemain yang mempunyai naluri untuk mencetak skor. Jadi, tembakan atau shooting adalah suatu usaha gerakan terakhir untuk mendapatkan angka dengan cara memasukkan bola ke keranjang lawan. Shooting terdiri dari beberapa teknik, antara lain jump shoot, lay up, setshoot, hook shoot, underhead shot, dunkin 
shot, reverse lay up shotdan segala macam gerakan dengan upaya memasukkan bola ke dalam ring Khoeron, (2017).

Shooting dalam permainan bolabasket sekilas terlihat sederhana namun sebenarnya adalah teknik yang tergolong kompleks diantara teknik lainya. Shooting (menembak) adalah keahlian yang sangat penting di dalam olahraga basket. Shooting memerlukan kordinasi gerak yang baik yang biasa disebut dengan BEEF (Balance, Eyes, Elbow,Follow throught) dimana posisi badan harus seimbang dengan pandangan mata menuju pada keranjang, kemudian siku membentuk sudut siku-siku 90 derajat dan diakhiri dengan gerakan lanjutan (follow throught).

Atas dasar fakta diatas untuk mengatasi agar kemampuan dasar melakukan shooting tersebut lebih baik maka perlu adanya model pembelajaran yang baik pula untuk keberhasilan saat proses pembelajarannya. Dilihat dari kriteria ketuntasan minimal (KKM) pada kelas 11 TKJ 7 SMKN 1 Palasah adalah 73. Jika peneliti prosentasekan siswa yang mencapai KKM hanya $32.3 \%$ dan siswa yang belum mencapai KKM 67,7\%. Oleh karena itu, guna untuk mencapai ketuntasan belajar maka perlu adanya model pembelajaran yang lebih baik lagi, agar para siswa mencapai ketuntasan dalam belajar.

Berdasarkan hasil pra-observasi yang penulis lakukan penulis menemukan masalahmasalah yang terjadi pada siswa/siswi disekolah SMKN 1 Palasah. Kurangnya kemampuan teknik dasar shooting dalam permainan bola basket. Dikarenakan pada guru seringkali memberikan metode pembelajaran yang pasif atau dengan cara pembelajaran konvensional dimana para guru hanya sebatas menyelesaikan tugasnya dengan sekedar memberikan sebuah materi sehingga tidak sedikit para siswa yang jenuh bahkan tidak dapat menerima dengan baik materi yang sudah disampaikan. Dengan itu para guru harus bisa mengembangkan model pembelajaran yang disampaikan kepada siswa agar siswa tidak bosan dengan pembelajaran yang disampaikan oleh gurunya sehingga siswa dapat menerima dengan baik materi yang telah disampaikan. Upaya untuk meningkatkan kemampuan teknik dasar shooting bola basket, salah satunya dengan cara mengembangkan suatu model pembelajaran.

Pembelajaran shooting yang adasaat ini kebanyakan dengan menggunakan pengajaran yang monoton sehingga anak merasa jenuh dan bosan. Namun ada sebagian guru yang menggunakan metode drill untuk proses pembelajarannya. Tapi metode drill yang gunakan belum maksimal. Pembelajaran shooting dengan metode drill yang sering diterapkan di sekolah-sekolah membuat para siswa kehilangan kesempatan melatih gerakan shootingnya ini dikarenakan pembelajaran dengan metode drill yang diterapkan memaksa siswa mengantri dan menunggu giliran untuk melakukan gerakan shooting, dengan demikian otomatis dalam satu kali pertemuan siswa hanya dapat sedikit melakukan gerakan shooting. Ini sangatlah berbeda 
dengan prinsip latihan drill dimana siswa harusnya melakukan gerakan shooting berulangulang sesering mungkin dengan frekuensi yang banyak. Jika frekuensi melatih gerakan shooting saat pembelajaran minim, ini akan berimbas pada hasil kemampuan teknik dasar para siswanya. Frekuensi yang banyak saat pembelajaran akan berdampak pada kemampuan teknik dasar siswanya. Disebut bermanfaat dikarenakan frekuensi yang bertambah saat pembelajaran akan meningkatkan kemampuan dasarshooting.

\section{Model Awal}

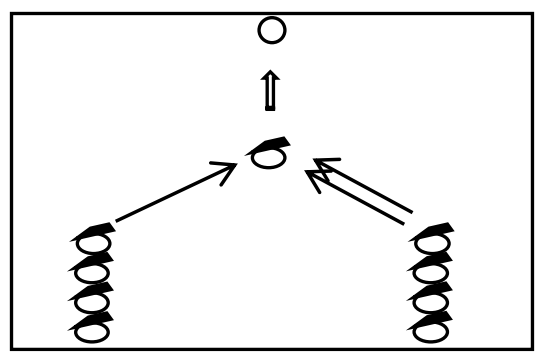

\section{Kekurangan :}

1. Antrian terlalu panjang.

2. Sedikit pengulangan shooting.

3. Gerakan shooting terlalu sedikit.

4. Pembelajaran terlalu monoton

\section{Alasan harus dikembangkan :}

1. Siswa di dalam antrian jenuh menunggu.

2. Harus banyak pengulangan shooting.

3. Sedikitnya gerakan shooting yang dilakukan oleh siswa

Dari penjelasan diatas peneliti menyimpulkan bahwa pembelajaran shooting konvensional yang diterapkan di sekolah SMKN 1 Palasah kurang efektif untuk menambah kemampuan teknik dasar shooting para siswa nya. Dari sinilah peneliti ingin mengembangkan pembelajaran tersebut menjadi lebih efektif dan memiliki banyak keunggulan. Peneliti menganalisis terlebih dahulu pada bagian apa saja yang dapat menghambat pada pembelajaran shooting konvensional. Peneliti akan mencoba menambah gerakan gerakan tambahan untuk menunjang proses pembelajaran. Yakni gerakan tambahan ini untuk mengisi kekosongan bagi siswa yang menunggu antrian. Dalam hal ini peneliti juga menambahkan variasi gerakan agar siswa tidak bosan dan jenuh menunggu.

Dalam penelitian ini peneliti bermaksud mengembangkan bentuk pembelajaran shooting konvensional yang sudah ada kemudian dicari kelemahannya oleh peneliti kemudian diganti dengan masukan baru yang menurut peneliti memiliki banyak kelebihan jika diterapkan dalam pembelajaran shooting tersebut. Dari model pembelajaran yang peneliti buat diharapkan 
bisa meningkatkan kemampuan teknik dasar keterampilan shooting bola basket oleh siswa Sekolah Menengah Atas (SMA).

Salah satu penyebab siswa merasa bosan dalam mengikuti pembelajaran shooting bola basket adalah pembelajaran yang konvensional. Dengan pembelajaran yang konvensional siswa juga harus menunggu antrian yang lama dalam mengikuti pembelajaran shooting bola basket. Maka dari itu, tidak semua siswa yang berkesempatan untuk melakukan shooting tersebut dikarenakan menunggu antrian dan waktu relatif singkat.

Fokus yang akan diambil adalah pada medium shoot. Karena dalam medium shoot jarak antara siswa dan ring tidak terlalu jauh, tidak terlalu dekat bagi siswa-siswi Sekolah Menengah Atas (SMA), dilihat dari semua siswa tidak semuanya siswa laki-laki, dan akan lebih balance jika menggunakan medium shoot dengan menggunakan metode drill dilihat dari siswanya ada yang perempuan juga. Sehingga dirasa perlu untuk diterapkan di dalam model pengembangan ini, agar kemampuan teknik dasar shooting siswa-siswinya meningkat.

\section{Model Yang Sudah Dikembangkan}

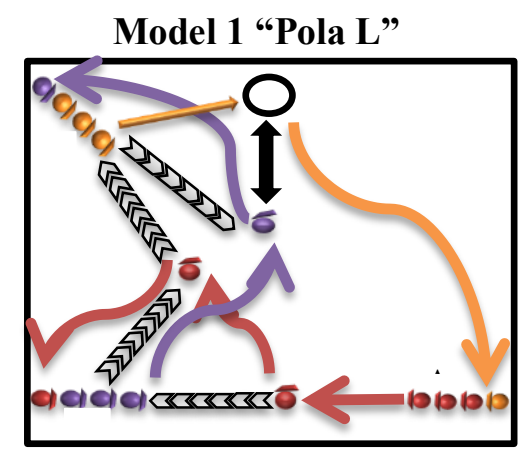

\section{Langkah-Langkah Model 1:}

1) Bola berjumlah 4 buah, 2) Dimainkan setengah lapangan bola basket, jadi model ini dilakukan 1 lapangan dengan 2 aktivitas, 3) Lalu tim A men-dribble bola ke arah tim B lalu tim A mem-passing kearah tim B, 4) Lalu tim A berlari ke arah tengah, lalu tim B mem-passing ke tim A, 5) Lalu tim A yang berada ditengah mem-passing kepada tim C. Lalu berlari memasuki barisan B, 6) Dan timB berlaring ke arah area ring, 7) Lalu tim C mem-passing kepada tim B, kemudian tim B melakukan shooting kearah ring. Jika sudah melakukan shooting langsung memasukin barisan tim $\mathrm{C}$, 8) Tim $\mathrm{C}$ melakukan ribbon dan Tim $\mathrm{C}$ men-dribble ke arah tim A.dan mem-passing kearah tim A lalu tim C memasuki ke barisan A, 9) Lebih tepat alurnya Tim A masuk ke arah tim B, Tim B masuk ke barisan tim C, tim C masuk ke barisan Tim A. 


\section{Model 2 "Pola Variasi"}

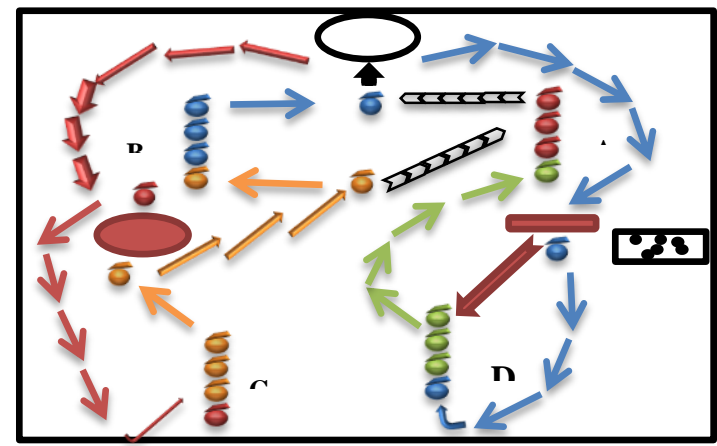

\section{Langkah-Langkah Model 2:}

Bola berjumlah 4, 2)Siswa dibariskan menjadi 4 kelompok, kelompok A,B,C dan D, 3)Siswa baris B melakukan cutting kearah depan ring, lalu baris A melakukan passing kepada siswa baris B yang berada di depan ring, 4) Siswa baris B melakukan shooting ke ring, dan siswa baris A melakukan rebound, 5) Siswa baris A lari ke arah barisan belakang baris B sambil melakukan Ball Handling, lalu melakukan shooting tiduran, 6) Siswa baris C lari kearah siswa baris A yang sedang malakukan shooting tiduran, siswa baris A shooting tiduran ke arah siswa baris C yang berada di depannya, 7) Siswa baris C menangkap bola dari lemparan siswa baris A, lalu siswa baris C melakukan Ball Handling ke arah tengah diantara siswa baris B dan A, 8) Siswa baris $\mathrm{C}$ melakukan passing ke barisan siswa A. Dan siswa C masuk ke barisan kelompok B, 9) Siswa barisan B yang tadi melakukan shooting lari ke arah belakang barisan siswa A, dan melakukan push up jari selama 3x, lalu siswa dari barisan B mengambil bola basket di sebelahnya untuk melakukan shooting parabol ke arah siswa barisan D, 10) Siswa barisan D menangkap bola, lalu menempatkan bola ke tempat pengumpulan bola, lalu siswa dari barisan B lari kearah belakang barisan D, lalu masuk ke barisan D, 11) Siswa dari barisan D yang tadi menangkap lari kearah siswa barisan A, 12) Lakukan berulang-ulang.

\section{Metode Penelitian}

Desain penelitian adalah rencana atau rancangan yang dibuat oleh peneliti, sebagai ancer-ancer kegiatan, yang akan dilaksanakan. Penelitian ini menggunakan metode penelitian dan pengembangan (Research and Development), yaitu penelitian yang digunakan untuk menghasilkan produk tertentu, dan menguji keefektifan produk tersebut. (Sugiyono, 2016).

Metode penelitian dan pengembangan dapat diartikan sebagai cara ilmiah untuk meneliti, merancang, memproduksi dan menguji validitas produk yang telah dihasilkan. Berdasarkan penelitian tersebut kegiatan penelitian dan pengembangan dapat disingkat menjadi 
4P (Penelitian, Perancangan, Produksi dan Pengujian). Dalam penelitian kali ini peneliti ingin meneliti da menguji untuk mengambangkan produk yang telah ada.

Metode pengembangan model pembelajaran shooting bolabasket untuk kelas 11 SMK N 1 Palasah ini menggunakan metode pengembangan dari Borg dan Gall. Peneliti memilih metode pengembangan ini berdasarkan kesesuaian produk yang akan dikembangkan dengan metode pengembangan yang digunakan.

Model ini dikenaldengan model sepuluh langkah. Berikut ini adalah kesepuluh langkah utama penelitian dan pengembangan yang dikemukan oleh Borg \& Gall, (1989) dalam Yuberti.

\section{RESEAROH and $R \& D$
DEVELOPMENT}

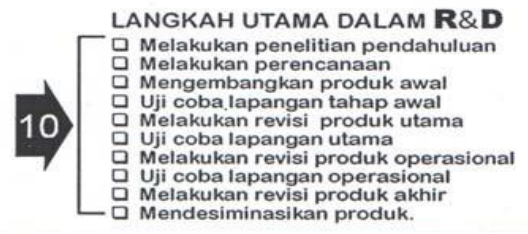

Menurut Ardhana, (2002) dalam Fathoni, prosedur pelaksanaan penelitian pengembangan bukan merupakan langkah-langkah baku yang harus diikuti secara baku, setiap pengembang tentu saja dapat memilih dan menemukan langkah-langkah yang paling tepat bagi dirinya berdasarkan kondisi khusus yang dihadapinya dalam proses pengembangan.

Adapun langkah-langkah metode penelitianResearch and Development (R \& D):

1) Melakukan penelitian model awal, 2) Pembuatan produk baru, 3) Validasi Ahli Pembelajaran dan Ahli Praktisi Basket, 4) Uji coba kelompok kecil, 5) Revisi hasil uji coba produk, 6) Uji coba kelompok besar, 7) Revisi produk berdasarkan kegiatan uji coba kelompok besar.

1. Validasi, Evaluasi dan Revisi Model

a. Validasi

Validasi produk dapat dilakukan dengan cara menghadirkan beberapa pakar atau tenaga ahli yang sudah berpengalaman untuk menilai produk baru yang dirancang tersebut. Pada penelitian ini peneliti akan menentukan ahli pembelajaran dan ahli basket guna untuk memvalidasi model peneliti.

b. Evaluasi

Produk pengembangan model pembelajaran yang akan diuji cobakan kepada subyek, produk yang dibuat dievaluasi (validasi) terlebih dahulu oleh ahli, kemudian diuji cobakan pada skala kecil yaitu dengan 16 siswa/siswi SMKN 1 Palasah. 
c. Revisi Model

Setelah melakukan uji coba skala kecil yaitu dengan 16 siswa/siswi maka dilakukan revisi sebagai perbaikan dari produk yang telah di uji cobakan. Setelah mendapat masukan dari ahli pembelajaran/praktisi bola basket, pada model draft 1 : Penambahan 2 buah Bola Basket dan pada model draft 2 :

1) 2 bola tambahan, dimaksudkan agar rotasi siswa/siswi lancar dan perputaran cepat,

2) 1 asisten guru, dimaksudkan untuk membantu mengumpulkan bola basket pada saat siswa melakukan push up 3 jari

Peneliti melakukan sedikit perubahan pada model pembelajaran shooting bola basket. Lalu peneliti menguji cobakan pada skala besar yaitu dengan 31 siswa/siswa SMKN 1 Palasah dengan memasukan saran dari ahli pembelajaran dan ahli praktisi basket. Setelah melakukan uji coba skala besar yaitu 31 siswa/siswi, maka selanjutnya pembuatan produk final untuk menyempurnakan model pembelajaran shooting bola basket.

\section{Teknik Analisis Data}

Teknik analisis data yang digunakan dalam penelitian pengembangan ini adalah menggunakan teknik analisis deskriptif presentase. Sedangkan data yang berupa saran dan alasan dalam memilih jawaban dianalisis menggunakan teknik analisis kualitatif. Dalam pengolahan data, persentase diperoleh dengan rumus dari Sudjadi (2004), yaitu:

Keterangan:

\section{$\mathbf{F}=\mathbf{f} / \mathbf{N} \times 100 \%$}

$\mathrm{F} \quad=$ frekuensi relatif/angkapersentase

$\mathrm{F} \quad=$ frekuensi yang sedang dicari persentasenya

$\mathrm{N}=$ jumlah seluruh data

$100 \%=$ konstanta

Dari hasil persentase yang diperoleh kemudian diklasifikasikan untuk memperoleh kesimpulan data.

Klasifikasi Persentase

\begin{tabular}{|c|c|c|}
\hline Persentase & Kategori & Makna \\
\hline $0-20 \%$ & Sangat Kurang & Dibuang \\
\hline $20,1 \%-40 \%$ & Kurang & Diperbaiki \\
\hline $40,1 \%-70 \%$ & Cukup & Digunakan (bersyarat) \\
\hline $70,1 \%-90 \%$ & Baik & Digunakan \\
\hline $90,1 \%-100 \%$ & Sangat Baik & Digunakan \\
\hline
\end{tabular}




\section{Hasil dan Pembahasan (12 pt)}

Dari hasil analisis peneliti, model pembelajaran yang telah dikembangkan diatas berhasil memenuhi kriteria-kriteria yang membuat model tersebut layak untuk diterapkan dalam pembelajaran shooting bolabasket dan dapat meningkatkan kualitas dalam melakukan shooting dalam permainan bola basket. Dari hasil penelitian ini, peneliti sudah dapat membuat model pembelajaran baru yang memiliki kelebihan-kelebihan dibandingkan dengan model pembelajaran terdahulu sebelum dikembangkan.

Dalam model pembelajaran baru yang telah dikembangkan ini peneliti berhasil membuat model pembelajaran yang benar-benar dibutuhkan oleh para siswa/siswi untuk dapat meningkatkan meningkatkan dan hasil belajar shooting bola basket. Model pembelajaran yang baru ini dibuat peneliti secara sederhana namun memiliki kelebihan-kelebihan dari model terdahulu sebelum dikembangkan.

Dalam model pembelajaran yang telah dikembangkan ini peneliti menambahkan drill (pengulangan) saat pembelajaran, ini dikarenakan drill (pengulangan) sangat berpengaruh terhadap hasil. Selain drill peneliti juga menambah gerakan-gerakan tambahan guna untuk menyempurnakan kedua model pembelajaran tersebut. Peneliti juga melakukan perubahan lain dalam model pembelajaran yang telah dikembangkan yaitu dengan menambah lamanya waktu pada saat siswa/siswi melakukan model pembelajaran shooting tersebut. Hal ini sangat dibutuhkan agar pada saat pembelajaran siswa/siswi dapat memaksimal kemampuan shooting mereka. Karena dengan bertambahnya waktu ini berarti meskipun waktu pembelajaran tidak terlalu lama tetapi pembelajaran tersebut bermutu dan berbobot ketimbang pembelajaran dengan waktu yang lama tetapi gerakannya sedikit. Peneliti menambahkan itu semua bukan tanpa alasan, perubahan tersebut dimasukkan karena memang dibutuhkan dalam proses pembelajaran.

Pada saat uji coba skala kecil di lapangan, siswa sangat tertarik dengan model pembelajaran yang di sampaikan oleh peneliti. Itu semua terlihat dari banyaknya siswa yang memperhatikan dengan teliti apa saja yang peneliti sampaikan tentang peraturan dan bagaimana cara kerja model pembelajaran tersebut. Pada uji coba skala kecil peneliti menggunakan 16 siswa/siswi dengan menggunakan4 bola basket. Setelah selesai siswa dibagikan angket tentang penilaian mereka terhadap model pembelajaran yang peneliti sampaikan tadi.

Respon peserta didik terhadap model pembelajaran shooting ini cukup antusias. Dimana terlihat para siswa ingin sekali mencoba dan terus mencoba pembelajaran shooting ini. Ini dikarenakan peserta didik merasa tidak bosan dan senang ketika melakukan pembelajaran 
shooting tersebut. Pembelajaran shooting ini memang dirancang agar peserta didik tidak cepat bosan dan jenuh dengan proses pembelajaran yang sedang berjalan.

Setelah selesai, peserta didik dibagikan angket penilaian terhadap model pembelajaran shooting yang telah mereka lakukan. Dari hasil angket yang telah di isi oleh peserta hasilnya para peserta memberikan respon positif terhadap model pembelajaran yang dibuat oleh peneliti. Ini terbukti dari hasil angket yang telah siswa kumpulkan.

\section{Model Final 1 "Pola L"}

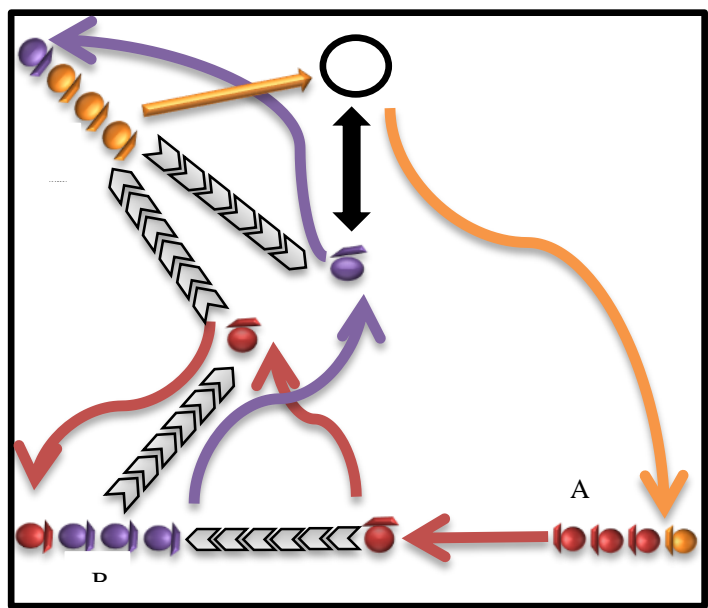

\section{Langkah-Langkah Model Final 1}

1) Bola berjumlah 6 buah, 2) Dimainkan setengah lapangan bola basket, jadi model ini dilakukan 1 lapangan dengan 2 aktifitas, 3) Lalu tim A men-dribble bola ke arah tim B lalu tim A mem-passing kearah tim B, 4) Lalu tim A berlari ke arah tengah, lalu tim B mem-passing ke tim A, 5) Lalu tim A yang berada ditengah mem-passing kepada tim C. Lalu berlari memasuki barisan B, 6) Dan timB berlaring ke arah area ring, 7) Lalu tim $\mathrm{C}$ mem-passing kepada tim $\mathrm{B}$, kemudian tim B melakukan shooting kearah ring. Jika sudah melakukan shooting langsung memasukin barisan tim $\mathrm{C}, 8)$ Tim $\mathrm{C}$ melakukan ribbon dan Tim $\mathrm{C}$ men-dribble ke arah tim A.dan mem-passing kearah tim A lalu tim C memasuki ke barisan A, 9) Lebih tepat alurnya Tim A masuk ke arah tim B, Tim B masuk ke barisan tim C, tim C masuk ke barisan Tim A.

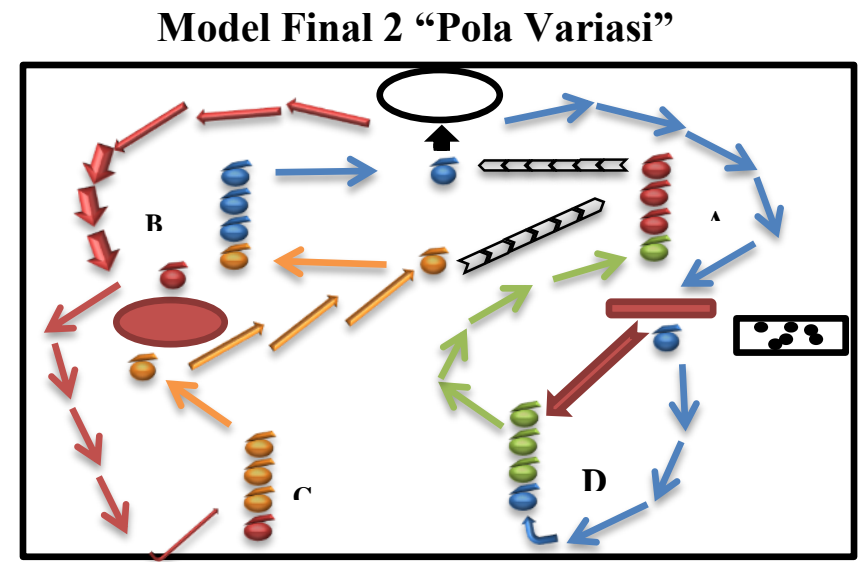




\section{Langkah-Langkah Model Final 2}

Bola berjumlah 6 buah, 2) Siswa dibariskan menjadi 4 kelompok, kelompok A,B,C dan D, 3) Siswa baris B melakukan cutting kearah depan ring, lalu baris A melakukan passing kepada siswa baris B yang berada di depan ring, 4) Siswa baris B melakukan shooting ke ring, dan siswa baris A melakukan rebound, 5)Siswa baris A lari ke arah barisan belakang baris B sambil melakukan Ball Handling, lalu melakukan shooting tiduran, 6) Siswa baris C lari kearah siswa baris A yang sedang malakukan shooting tiduran, siswa baris A shooting tiduran ke arah siswa baris C yang berada di depannya, 7) Siswa baris C menangkap bola dari lemparan siswa baris A, lalu siswa baris C melakukan Ball Handling ke arah tengah diantara siswa baris B dan A, 8) Siswa baris C melakukan passing ke barisan siswa A. Dan siswa C masuk ke barisan kelompok B, 9) Siswa barisan B yang tadi melakukan shooting lari ke arah belakang barisan siswa A, dan melakukan push up jari selama 3x, lalu siswa dari barisan B mengambil bola basket di sebelahnya untuk melakukan shooting parabol ke arah siswa barisan D, 10) Siswa barisan D menangkap bola, lalu menempatkan bola ke tempat pengumpulan bola, lalu siswa dari barisan B lari kearah belakang barisan D, lalu masuk ke barisan D, 11) Siswa dari barisan D yang tadi menangkap lari kearah siswa barisan A, 12) Lakukan berulang-ulang.

\section{Kelayakan Model}

1. Kelayakan Model Secara Teoritik

Berbicara tentang kelayakan model, peneliti akan berusaha menjabarkan model yang telah di buat sehingga model tersebut disebut layak diterapkan dalam proses pembelajaran dan model yang telah dikembangkan tersebut dapat menutupi kekurangan-kekurangan dari model pembelajaran shooting konvensional terdahulu. Model tersebut dikatakan layak jika telah berkembang lebih baik dan memiliki banyak kelebihan dari model terdahulu sebelum dikembangkan.

Kelayakan model ini dibagi menjadi dua bagian yaitu secara teoritik dan secara empirik. Secara teoritik berarti model tersebut dikatakan layak jika didukung oleh pernyataan atau pendapat ahli yang berpengalaman dalam bidangnya. Sedangkan secara empirik adalah melihat hasil dilapangan apakah model tersebut disukai siswa dan membuat siswa nyaman atau tidak. Kelayakan model pengembangan pembelajaranshooting bolabasket, langkah selanjutnya yang ditempuh adalah validasi ahli pembelajaran dan ahli praktisi bola basket.

Berdasarkan hasil evaluasi dan revisi para ahli dapat diketahui bahwa Ahli Pembelajaran skor kualitas pada model 1 dan model 2 dalam kategori "Baik" dengan rata- 
rata persentase 88,8\%, dan Ahli Praktisi Basket skor kualitas pada model 1 dan model 2 dalam kategori "Baik" dengan rata-rata persentase 83,3\%.

\section{Kelayakan Model Secara Empirik}

Berdasarkan hasil validasi dari ahli pembelajaran dan ahli praktisi basket maka selanjutnya adalah melakukan uji coba skala kecil dan skala besar dengan 16 siswa dan 31 siswa kelas 11 TKJ 7 SMK N 1 Palasah. Siswa diberi angket dan diminta untuk menilai tingkat kesulitan item pembelajaran. Hasil angket penilaian siswa dalam uji coba skala kecil dan skala besar yaitu dengan 16 siswadan 31 siswa kelas 11 TKJ 7 SMK N 1 Palasah.

Secara keseluruhan pada uji coba skala kecil 16 siswa dapat diketahui bahwa skor kualitas model 1 dalam ketegori "Baik" dengan rata-rata persentase 89.5\%, dan pada model 2 dalam kategori "Baik" dengan rata-rata persentase 85.6\%.Jika hasil keseluruhan nilai yang diperoleh dari hasil penelitian skala kecil pada model 1 dan 2 dapat diketahui mencapai kategori "Baik" dengan rata-rata prosentase $87,5 \%$.

Secara keseluruhan pada uji coba skala besar 31 siswa dapat diketahui bahwa skor kualitas model 1 dalam ketegori "Sangat Baik" dengan rata-rata persentase 91.6\%, dan pada model 2 dalam kategori "Baik" dengan rata-rata persentase 89.3\%.Jika hasil keseluruhan nilai yang diperoleh dari hasil penelitian skala besar pada model 1 dan 2 dapat diketahui mencapai kategori "Sangat Baik" dengan rata-rata prosentase 90,5\%

\section{Kesimpulan}

Berdasarkan model pembelajaran yang peneliti buat, peneliti mengambil kesimpulan bahwa model 1 "Pola L" dan model 2 "Pola Variasi yang telah dibuat tersebut telah sesuai dengan tujuan akhir yaitu membuat model pembelajaran shooting yang efektif dan efisien sehingga pada saat siswa/siswi melakukan shooting bisa maksimal dan mendapatkan hasil terbaik dari pembelajaran tersebut. Dengan kelebihan-kelebihan yang dimiliki oleh model pembelajaran baru tersebut bukan tidak mungkin model pembelajaran pembelajaran shooting yang baru itu akan diterapkan di beberapa SMA/SMK.

Tidak ada sesuatu di dunia ini yang sempurna, begitupun model pembelajaran shooting bola basket yang telah dibuat oleh peneliti. Peneliti sadar bahwa model pembelajaran yang dibuat ini masih belum 100\% sempurna maka dari itu peneliti berharap masukan dari pihak lain yang sekiranya mempunyai masukan positif untuk dapat kembali mengembangkan model pembelajaran shooting tersebut. Adapun saran berdasarkan penelitian dan pengembangan ini, maka dapat disarankan hal-hal sebagai berikut: 
1. Mengingat hasil model penelitian dan pengembangan dapat memberikan manfaat bagi pembelajaran, maka disarankan kepada guru untuk mengembangkan model tersebut.

2. Perlu dilakukan pengembangan lebih lanjut terhadap model pembelajaran shooting guna meningkatkan kualitas dalam pembelajaran shooting bola basket.

\section{Daftar Pustaka}

\section{Daftar Pustaka}

Badriah, D. L. (2012). Metodologi Penelitian Ilmu-ilmu Kesehatan. Bandung : Multazam.

Budiman I. A. (2011). Hand Out Teori Belajar Motorik. Majalengka :Universitas Majalengka

Hamdani. (2010). Strategi Belajar Mengajar . Bandung : CV Pustaka Setia

Harjanto. (2006). Perencanaan Pembelajaran. Jakarta: Rineka Cipta

Juliantine, T. (2013). Model Pembelajaran Penjas. Bandung: Universitas Pendidikan Indonesia

Khoeron, N, (2017). Buku Pintar Basket. Jakarta : Anugrah.

Mahardi, Y. P. (2016). Pengembangan Model Latihan Shooting Untuk Meningkatkan Keterampilan Medium Shoot. Prodi Pendidikan Jasmani Kesehatan dan Rekreasi,Jurusan Pendidikan Olahraga, Fakultas Ilmu Keolahragaan, Universitas Negeri Yogyakarta.

Nurdian, A (2016). Pengaruh Model Pelatihan Half Moon Shooting dan Knockout Shooting Terhadap Shooting Free Throw Pada Pemain Tri Darma Jombang. Program Studi Pendidikan Jasmani dan Kesehatan STKIP PGRI Jombang. Vol 4 No.3 2016.

Rusman. (2014). Model-model Pembelajaran. Jakarta : Rajagrafindo Persada

Salim, A. (2007). Buku Pintar Bola Basket. Bandung : Penerbit Jembar 